\title{
Author Correction: Percutaneous management of paravalvular leaks
}

Joel P. Giblett, Bushra S. Rana, Leonard M. Shapiro and Patrick A. Calvert

Nature Reviews Cardiology (2019) https://doi.org/10.1038/s41569-018-0147-0 Published online 18 January 2019

In the version of this article initially published online, the Paravalvular Leak Device (PLD; Occlutech) was incorrectly described as having a "proximal disc that is slightly larger than the distal disc", whereas the distal disc is actually slightly larger than the proximal disc. This error has been corrected for the HTML, PDF and print versions of the article.

https://doi.org/10.1038/s41569-019-0184-3 I Published online 18 March 2019

\section{Author Correction: Permanent His bundle pacing: shaping the future of physiological ventricular pacing}

Parikshit S. Sharma®D, Pugazhendhi Vijayaraman and Kenneth A. Ellenbogen

Nature Reviews Cardiology (2019) https://doi.org/10.1038/s41569-019-0224-z Published online 27 June 2019

In the version of this article initially published online, the four images of electrograms in Figure 2

were incorrectly labelled. From left to right, the correct labels are: Proximal to LBB delay, Non-selective HBP without correction of LBBB,

Selective HBP with correction of LBBB and Distal to LBB delay. This error has been corrected for the HTML, PDF and print versions of the article.

https://doi.org/10.1038/s41569-019-0240-z I Published online 11 July 2019

\section{Publisher Correction: The autonomic nervous system and cardiac arrhythmias: current concepts and emerging therapies}

\section{Neil Herring (1), Manish Kalla and David J. Paterson (1)}

Nature Reviews Cardiology (2019) https://doi.org/10.1038/s41569-019-0221-2 Published online 13 June 2019

In the version of this article initially published online, the survival curves in the graph in Figure 5 b were incorrectly labelled. The correct labels are: Left CSD (blue line) and Bilateral CSD (red line). This error has been corrected for the HTML, PDF and print versions of the article.

\section{Publisher Correction: The autonomic nervous system and cardiac arrhythmias: current concepts and emerging therapies}

Neil Herring (D, Manish Kalla and David J. Paterson (D)

Nature Reviews Cardiology (2019) https://doi.org/10.1038/s41569-019-0221-2 Published online 13 June 2019

In the version of this article initially published online, in Figure 3, the text in the grey box on the right-hand side of the 'Intrinsic cardiac ganglia' area (in light blue) was incorrect. The correct text for this box is 'Efferent parasympathetic neurons'. This error has been corrected for the HTML, PDF and print versions of the article.

https://doi.org/10.1038/s41569-019-0297-8 I Published online 8 October 2019 